\title{
Adolescência em atos e adolescentes em ato na clínica psicanalítica
}

\author{
Vládia dos Santos Jucáa* \\ Angela Maria Resende Vorcarob \\ aUniversidade Federal da Bahia, Instituto de Psicologia. Salvador, BA, Brasil \\ 'Universidade Federal de Minas Gerais, Departamento de Psicologia. Belo Horizonte, MG, Brasil
}

\begin{abstract}
Resumo: $\mathrm{O}$ artigo apresenta uma reflexão teórica sobre a experiência clínica com adolescentes atendidos em um Centro de Atenção Psicossocial à Infância e à Adolescência (CAPSi). Os jovens chegaram ao CAPSi em função de automutilações, tentativas de suicídio, fugas e impulsividade expressa através da agressividade. Esses eventos são discutidos por meio dos conceitos lacanianos de "acting out" e de "passagem ao ato" e da antropologia de Le Breton. Observamos que os atos se apresentavam em três situações: (1) quando o jovem aparecia como objeto de um gozo mortífero; (2) perante a inconstância do Outro prestativo; (3) quando não era possível formular de outro modo a questão do significado e do valor de si para o Outro. Defendemos que os atos como na adolescência podem ser lidos como um apelo diante dos impasses vivenciados na busca de novos modos de se inscrever no campo social.
\end{abstract}

Palavras-chave: adolescência, psicanálise, passagem ao ato, acting out, CAPSi.

Propomos, neste escrito, abordar reflexões teóricas oriundas de um campo de extensão e investigação instituído entre o ensino universitário (Universidade Federal da Bahia) e um Centro de Atenção Psicossocial à Infância e à Adolescência (CAPSi), franqueado pela clínica psicanalítica de adolescentes. Importa elucidar a origem dessa proposta, implementada no serviço em questão no início de 2015, pois a sua pertinência é fruto da experiência com a problemática do acolhimento e do tratamento psíquico de adolescentes no CAPSi ${ }^{1}$.

Ao longo do tempo, as diversas inserções nesse equipamento que integra a rede municipal de assistência à clientela infantojuvenil pertencente ao Sistema Único de Saúde permitiram acompanhar mudanças importantes referentes à gestão e à equipe. Para fins deste artigo, interessa problematizar as novas demandas apresentadas pelos adolescentes e, a partir dessas transformações, refletir acerca da prática clínica. Entre os anos de 2013 e 2014, o quantitativo e a gravidade dos casos de adolescentes encaminhados ao serviço por suas constantes atuações começaram a chamar atenção dos profissionais. Ganharam preponderância os atos mais diversos: as automutilações (com destaque para as escarificações), as tentativas de suicídio, as fugas e, no contexto da rua, o colocar-se em situação de risco, bem como os atos impulsivos, com destaque para a auto e heteroagressividade.

Além das atuações se constituírem como o principal motivo para o acolhimento dos adolescentes, era notória a inquietação dos técnicos sobre como trabalhar com esse público, em particular. A operatividade da prática parecia

* Endereço para correspondência: vladiajuca@gmail.com

1 A primeira autora do artigo foi trabalhadora desse CAPSi, entre os anos de 2004-2005, integrando a equipe que implementou o serviço. Retornou ao centro em 2008, na condição de preceptora da residência de saúde mental coletiva pelo Instituto de Saúde Coletiva da Universidade Federal da Bahia (UFBA) e, a partir de 2013, implementou um programa de estágio enquanto docente do Instituto de Psicologia (IPS-UFBA). fracassar no sentido de romper com um circuito fechado, através do qual alguns adolescentes atuavam cada vez mais. Atestava-se também, por parte dos adolescentes, a dificuldade em narrativizar seu sofrimento. Foi por um interesse em entender o que leva os adolescentes a elegerem as atuações como modo de expressão do mal-estar, acrescido do desejo de sustentar uma oferta clínica a partir da psicanálise para esses jovens, que nasceu o projeto de extensão e de pesquisa. O projeto teve início em fevereiro de 2015, mas apenas recentemente, com o avanço do trabalho e das leituras, foi possível batizá-lo com o título Adolescência em atos: a clínica com jovens em um Centro de Atenção Psicossocial à Infância e a Adolescência (CAPSi), em Salvador, BA.

Portanto, os adolescentes com os quais trabalhamos têm em comum suas frequentes atuações. No entanto, não é possível negligenciar outras particularidades que esses jovens compartilham com a clientela atendida no CAPSi. No serviço, são atendidos majoritariamente crianças e adolescentes provenientes de famílias com baixa renda, mas que contam com recursos materiais para suprir necessidades básicas, têm acesso à educação, à saúde e ao lazer, além de disporem de uma rede social com a qual podem contar. Contudo, são acompanhados também de outras crianças e adolescentes em situação de extrema vulnerabilidade social, por vezes, com outros casos de sofrimento psíquico na família. A vulnerabilidade e os problemas familiares, agravados por um histórico de desassistência, levam, em situações extremas, ao abrigamento.

Em sua face de extensão, esse projeto oferta atendimento gratuito aos jovens. Com esse movimento, orienta-se para a pesquisa ${ }^{2}$, pois pretende aprender com tal prática clínica. Aprender na perspectiva de produzir um

2 O projeto de pesquisa foi submetido à Plataforma Brasil e aprovado pelo Comitê de Ética e Pesquisa do Instituto de Saúde Coletiva da Universidade Federal da Bahia com o CAAE: 39546514.1.0000.5030. 
saber sobre essa inflação do ato como via de expressão do sofrimento e de apelo dirigido ao outro; e, ainda, refletir acerca das estratégias clínicas mais pertinentes ao atendimento do público em questão. Quanto às estratégias clínicas, vale ressaltar que o adolescente é inicialmente acolhido na instituição por seus técnicos; o caso é discutido em reunião de equipe, na qual é eleito um técnico de referência, responsável pela gestão do projeto terapêutico singular (PTS). Caso se julgue pertinente, o adolescente terá $o$ atendimento individual realizado por um dos membros da equipe de extensão. $\mathrm{O}$ atendimento clínico ofertado insere-se, portanto, no PTS do adolescente. De qualquer modo, o trabalho é realizado em uma perspectiva multiprofissional e o diálogo com profissionais de outras áreas, presentes no acompanhamento de um caso específico, é uma constante. Por se tratar de um CAPSi, com uma clientela comumente marcada tanto pelo sofrimento psíquico quanto pela vulnerabilidade social, faz-se necessário o trabalho em rede, através do diálogo com a escola, com equipamentos pertencentes ao Sistema Único de Assistência Social (Centro de Referência de Assistência Social (CRAS), Centro de Referência Especializado de Assistência Social (CREAS) ou abrigos), bem como outros dispositivos do setor jurídico (Brasil, 2007). A depender da complexidade do caso, o trabalho em rede poderá demandar um maior investimento.

Ao tomar como ponto de partida a prática clínica desenhada nos termos citados, estamos interrogados pela manifestação enigmática desses jovens e, sobre isso, almejamos produzir um saber. Saber este que vai se tecendo em um constante exercício sobre o atendimento psicanalítico com os adolescentes, o qual suscita reflexões várias. Destacamos três: (1) o conceito de adolescência para a psicanálise; (2) o lugar do diagnóstico na prática clínica com esses sujeitos; e (3) o entendimento do que os atos cometidos pelos adolescentes revelam acerca do seu sofrimento e do nosso tempo. Os três campos reflexivos destacados serão abordados de modo articulado e, por esse motivo, optamos por não dividir o texto em tópicos.

Para compartilhar as reflexões desenvolvidas, é fundamental explicitar algumas orientações e pressupostos que nos guiam, demarcando os horizontes teóricos e políticos que nos permitirão seguir em direção aos pressupostos com os quais operamos. As referências que norteiam o trabalho da extensão e da pesquisa são oriundas de três campos: a psicanálise, com destaque para os autores que se ocupam dos adolescentes; a antropologia, em particular as contribuições de David Le Breton; e as políticas públicas voltadas para a infância e para a adolescência, atualmente orientadas pela perspectiva da atenção psicossocial, com grande ênfase para o trabalho em rede. Não obstante esse tenha sido o tripé da extensão e da pesquisa realizadas, este artigo - em função do recorte eleito para sua confecção - trabalhará a partir das duas primeiras referências.

$\mathrm{O}$ primeiro ponto a elucidar diz respeito à diferença entre puberdade e adolescência na teoria psicanalítica. A puberdade seria um conjunto de mudanças corporais disparadas a partir da maturação biológica, que caminha no sentido da aptidão física para a reprodução. A adolescência vem a reboque da puberdade, tratando-se de um evento socioculturalmente circunscrito. Nas balizas dadas pelo contexto, a adolescência é um tempo precioso, no qual questões muito elementares do processo de estruturação psíquica serão retomadas.

Na defesa desse modo de pensar a adolescência, Bernardino (2004) resgata Lacan (1945/1998) em seu texto "O tempo lógico e a asserção de certeza antecipada", no qual o autor trata de três tempos: "o instante do olhar", "o tempo para compreender" e "o momento de concluir" - a fim de pensar a adolescência como um tempo de concluir. No texto referido, Lacan apresenta os três tempos, a partir do sofisma, para demonstrar como cada tempo se articula com outro, para além de uma ordem cronológica, instituindo uma lógica que permite a sustentação de um determinado raciocínio. Lacan, nesse texto, não estabelece uma associação entre o tempo de concluir e a adolescência - vale ressaltar o fato de que essa é uma tomada de posição clínica, que se desenha a partir das construções de autores que se servem de Lacan para pensar o seu fazer no trabalho com crianças e adolescentes.

Pensar a adolescência como um tempo de concluir traz à tona a necessidade de pensar o processo de constituição psíquica no enlace entre dois tempos: o tempo lógico e o tempo cronológico, ou seja, é considerar que diacronia e sincronia se articulam para que possa advir um sujeito. Destacamos que se trata de um modo de pensar, porque não há consenso entre os autores da psicanálise sobre esse ponto, conforme apontou Bernardino (2004) na revisão acerca das posições controversas no que tange a questão do desenvolvimento humano na teoria psicanalítica. Nessa revisão, a autora também se posiciona e, pensando com os que acreditam na pertinência de se considerar os dois tempos - o lógico e o cronológico -, sustenta uma hipótese de trabalho da qual compartilhamos:

há momentos-chave na definição da estrutura. A estrutura, do nosso ponto de vista, não seria um dado, a priori, nem se definiria a partir de um único momento de inscrição. É, muito mais, a resultante de um processo de construção, composto por diversas operações psíquicas essenciais - aí compreendendo o entrecruzamento dos tempos lógico e cronológico - que pressupõem a relação com um outro da espécie, agente que desempenha a função do Outro (p. 36).

Tendo elucidado o que Bernardino, a partir de sua prática clínica, apresenta como hipótese e que, para fins deste artigo, será tomado como pressuposto, vale retomar a proposição segundo a qual a adolescência seria um "tempo de concluir", mas cabe aqui duas perguntas: concluir o quê? E, uma vez realizada a conclusão, esta teria valor de ponto final, não sendo mais possível nenhuma modificação - ou seja, os dados estariam definitivamente lançados?

Para responder tais questões, vamos recorrer a Vorcaro e Capanema (2011) que, apoiadas em Rassial (1999), afirmam ser a adolescência um momento de amarração entre 
o real, o simbólico e o imaginário a partir de um quarto elo: o nó borromeu. Trabalhar a partir dessa perspectiva nos auxilia na tentativa de responder, mesmo que provisoriamente, as indagações apresentadas. Talvez a adolescência seja um tempo de concluir - no sentido de definir um modo de funcionamento psíquico no laço social sem a mediação da família. No entanto - em se tratando de um nó que se enreda na trama das outras articulações, sustentando de modo único as três instâncias conjuntamente-, é importante salientar certa provisoriedade, sendo possível a ocorrência de rupturas e a "desorganização" de uma montagem, na qual se equilibrava um sujeito.

$\mathrm{Na}$ tentativa de responder as questões postas, rapidamente outra pergunta se impõe: a compreensão apresentada nos faz prescindir de uma compreensão estrutural classificatória da psiquê? Ou seja, é possível trabalhar na clínica psicanalítica priorizando o sujeito e a resposta por ele construída, deixando assim, em segundo plano, as estruturas utilizadas pelo próprio Lacan, em particular, no primeiro momento de sua obra? Não é uma questão fácil. O desafio teórico e prático é grande. Afinal, ao trabalhar com a perspectiva lacaniana comumente se aprende a realizar o raciocínio clínico, adotando como ponto de partida as estruturas (psicose, neurose e perversão), apesar dos próprios desdobramentos da teoria lacaniana e da problematização acerca da dificuldade de classificar alguns casos. Ao mesmo tempo, ter como princípio essa classificação para nela anexar os atos cometidos pelos adolescentes é pressupor que o inconsciente foi plenamente lido e que $o$ destino desses sujeitos está dado de antemão. Na medida em que a clínica só opera cortes contingentes, ela estaria então limitada e definida pelo diagnóstico.

Refletir sobre os atos realizados pelos adolescentes requer pensar os impasses vividos por cada um e desencadeados pelo real da puberdade, a partir de um pano de fundo que seria o campo social, marcado pelo discurso capitalista, do qual falaremos a seguir. Do ponto de vista ainda do pensamento clínico, os atos têm também o potencial de desvelar os limites de uma leitura restrita às grandes estruturas.

Estudar os atos na adolescência nos permite analisar os impasses de cada jovem na ampliação dos seus laços sociais (em decorrência de sua posição na relação com o Outro); a cultura contemporânea e; a importância de se aprofundar o olhar no caso a caso, sem tomá-los apenas como demonstração do que se sabe aprioristicamente pela inferência de uma estrutura da base. Sobre este último ponto, é fundamental lembrar que adolescentes são sujeitos em constituição, imersos no "tempo de concluir".

Nessa direção, é interessante retomar a reflexão iniciada sobre adolescência e temporalidade. Se, por um lado, o adolescer precisa ser entendido, no cruzamento do tempo lógico e do cronológico - pelo menos, assim defendemos -, é fundamental, por outro ângulo, lembrar que, enquanto fenômeno social, a adolescência de modo algum escapa a seu tempo. Aliás, ela própria é fruto de um processo histórico iniciado entre os séculos XVIII e XIX. De qualquer modo, o uso do termo adolescência para designar mais claramente uma etapa da vida passa a vigorar a partir do século XIX. Mesmo assim, em Freud, como aponta Vieira (2014) através de uma leitura sistemática dos textos do autor, não existe uma distinção claramente estabelecida no emprego dos termos puberdade e adolescência. Predomina, na obra freudiana, o vocábulo puberdade, fase que se seguiria ao período de latência.

Ao considerar o contexto no qual a adolescência se produz, destacamos, para fins deste trabalho, a diferença significativa das sociedades contemporâneas ocidentais e individualistas para as mais tradicionais. Nas sociedades nomeadas como tradicionais, os ritos de passagem envolviam atos que ora marcavam o corpo ora extraiam algo desse corpo, por exemplo, a escarificação ou extração de dentes (Le Breton, 2011). Nas sociedades tradicionais era, portanto, através de uma "cirurgia do sentido" que o púbere saía da infância e entrava na vida adulta. Cirurgia ritualística de caráter preciso e relativamente rápida, se compararmos com o tempo destinado à adolescência na nossa cultura. Nas sociedades individualistas, não apenas ocorreu uma distensão de um tempo que passou a ser tomado como "adolescência", mas outra mudança significativa se colocou: os ritos coletivos que demarcavam a passagem para a vida adulta se perderam. Como afirma Le Breton (2011): "Tornar-se um homem e uma mulher não é mais ritualizado, mas se efetua por um caminho pessoal. A adolescência é sobretudo um sentimento" (p. 7). Na ausência de ritos coletivos, cabe aos adolescentes utilizarem-se da linguagem e das ferramentas de seu tempo para fazerem a transição, circulando, por um lado, entre espaços grupais, como as redes sociais e, por outro, vivendo a experiência de se tornar homem e se tornar mulher solitariamente, preço pago para se moldar como único em uma sociedade de indivíduos. $\mathrm{O}$ adolescente hoje faz suas próprias marcas.

A adolescência, na sociedade de indivíduos, com sua temporalidade ampliada e na ausência de ritos coletivos, é marcada por acontecimentos importantes: a imagem corporal é reconstruída (portanto, as fronteiras do "eu" se fragilizam); as questões edipianas são revividas; o encontro com o sexo levará a constatação de que a completude imaginária é da ordem do impossível; e - não menos importante - o funcionamento psíquico bem como o laço com o outro ganham contornos mais definidos.

Portanto, adolescer diz respeito a um tempo de intenso trabalho psíquico. Assim, concordamos com Lesourd (2004) que prefere chamá-la de "operação adolescente". Pela referida operação, o adolescente busca inscrever-se por meio de novos significantes no campo do Outro. A adolescência pensada como uma operação é:

a passagem entre o discurso infantil referido ao Pai para os discursos sociais referidos ao Outro social. O remanejamento imposto por esta passagem entre duas formas de referência implica um remanejamento da organização psíquica e da relação do sujeito com o mundo (Lesourd, 2004, p. 14). 
Os jovens com os quais trabalhamos no projeto são a princípio indivíduos que se constituíram na tessitura da cultura contemporânea e estão, por assim dizer, embaraçados na transição implicada no adolescer. Comumente, através de seus atos, denunciam algo que não vai bem em sua relação com os outros. Traduzem em ação o que, naquele momento, não cabe em palavras. Quando falam, revelam-se questões recorrentes sobre: a imagem corporal, a posição diante do sexo, ao apartar-se de seus pais (ou dos que ocuparam o lugar do Outro primordial). Em muitos casos, aquilo que do infantil não pôde ser elaborado retorna com uma nova potência: a do corpo que cresceu e se encontra submetido aos excessos pulsionais. $\mathrm{Na}$ clínica, nosso desafio é justamente auxiliar o adolescente na sua travessia, sem que se pague um preço tão elevado, por vezes, colocando em risco sua própria vida.

Para trabalhar com adolescentes, é preciso, por um lado, ter a delicadeza de reconhecer que a adolescência não é a mesma para todos e, por isso, é necessário ter muita cautela com generalizações como aquelas que posicionam de antemão o adolescente no lugar de um rebelde. Assim, é preciso observar como se efetiva a transição para cada um. Por outro lado, sustentamos a hipótese de que há algo em comum: a adolescência como operação na qual definições importantes irão se processar. Além disso, agregamos aqui um outro elemento: a compreensão de que a adolescência também nos revela algo do seu tempo. Cabe então uma reflexão sobre os motivos pelos quais os atos se tornaram tão recorrentes na clínica com adolescentes hoje. Se temos uma repetição que não é apenas de um, mas que se apresenta como sendo pertencente a vários de uma mesma geração, é preciso atentar para o que está sendo denunciado acerca do campo social no qual os adolescentes estão inseridos.

Defendemos essa posição em consonância com o que Rassial (2000) afirma ser a dupla face da adolescência. Em suas palavras, a adolescência: "é ao mesmo tempo operação psíquica tão fundamental quanto as primeiras identificações e testemunho exemplar do estado de uma civilização" (p. 30). Rassial (2000) e Lesourd (2004) concordam em dois pontos: a adolescência tende a se configurar com um tempo de intenso trabalho psíquico e é reveladora do nosso funcionamento social. A adolescência denuncia, desvela aos nossos olhos, algo que pertence a nosso tempo e a nossa cultura.

Trata-se de uma denúncia que não necessariamente se exerce pela "rebeldia". O próprio Lesourd (2004) nos fornece um exemplo de uma adolescente que, aos doze anos, pede à sua mãe para fazer uma plástica no nariz e tem seu pedido atendido. Segundo o autor, o estranhamento da adolescente com seu próprio corpo é esperado. No entanto, chama atenção o fato de que o Outro social, aqui representado pela mãe e pelo cirurgião, prontamente atenda o pedido. Por um ato cirúrgico, concretiza-se uma intervenção radical em um corpo em mutação. Um corpo cuja imagem está em plena reconstrução. Considerando que se trata de uma garota de doze anos, a decisão por fazer uma cirurgia poderia ser adiada. Se não o é, e se a adolescente tem prontamente seu pedido atendido, há algo a ser pensado a partir da resposta do Outro.
A cirurgia plástica se coloca em nossa cultura como um bem a ser consumido. Um bem bastante particular, porque se trata de consumir (ou construir) uma imagem corporal. De qualquer sorte, desse exemplo, o que nos interessa destacar é o fato do adolescente revelar, através de alguns apelos, um modo específico de relação com o objeto, muito presente na sociedade atual. Acerca da relação do adolescente com os objetos, vejamos o que nos diz Lesourd (2004):

Em primeiro lugar, o objeto se encontra na realidade. É definido por suas qualidades materiais, sua textura, sua forma, sua utilidade para o indivíduo e para a sociedade. Esse objeto da realidade está fortemente presente na nossa sociedade de consumo, que fez dele o centro das relações de troca, e até um dos sinais maiores do sucesso e do valor do indivíduo. $\mathrm{O}$ adolescente é ávido deste tipo de objeto, seja sob a forma de vestuário ..., sob a forma consumível . .., ou ainda a forma "emprestável", nos fenômenos de furto. Ele é ao mesmo tempo objeto da realidade, mas também marca social de sucesso ou pertencimento. $\mathrm{O}$ adolescente pode manter dois tipos de relações com esses objetos da realidade . . . Ele pode, seja consumi-los, o que o inclui no laço social dominante, o consumo; seja criá-los, o que então nos leva para as questões da criatividade, ou mesmo do artístico (p. 95).

Pela via do consumo, o adolescente denuncia o discurso capitalista e seu imperativo: Goze! O discurso capitalista foi uma quinta forma de discurso proposta por Lacan (1972), no Discurso de Milão, que se agrega aos quatro discursos anteriormente apresentados pelo autor (Lacan, 19691970/1992) - o da histérica, o do analista, o universitário e o do mestre. Na formulação algébrica lacaniana desses discursos, trata-se da redução algorítmica radical do ordenamento produzido pela existência da linguagem, fazendo função de laço social. A partir da raiz da formulação do elemento $U m$, que faz com que o significante funcione $\left(\mathrm{S}_{1}\right)$ estruturando o mundo - e, portanto, todo o saber $\left(\mathrm{S}_{2}\right)$ do ser falante, distinguindo-se os pontos de contato que fazem limite aos efeitos do significante na determinação do sujeito dividido (\$) e no seu produto, a causa do desejo (a), impossível de ser detida, sempre deslizante. $\mathrm{O}$ funcionamento desses termos em quatro lugares específicos, a partir do posicionamento do $\mathrm{S}_{1}$, ordena e diferencia os distintos discursos: "é a partir daí que há emissão de existência como algo que está também no nível do objeto $a$ pelo qual o sujeito se divide" (Lacan, 1972, p. 20).

No discurso do mestre, a fala é instrumento de poder que, na conexão $S_{1} \rightarrow S_{2}$ age sobre o sujeito realizando uma perda radical de si mesmo, que institui o objeto a como resto, causa do desejo, oferecido ao mestre. Na atualidade, à globalização do saber apropriado, foi agregado um valor de mercado que, adquirindo um estatuto de objeto acessível, torna o saber um bem de consumo desejado com avidez, podendo ser consumido de acordo com as leis do 
mercado. O sujeito passa a ocupar um lugar de dominância, acreditando-se capaz de comandar o objeto que the garante certo tipo de gozo: mais-de-gozar. O significante-mestre, por sua vez, aloca o lugar da verdade, numa relação ao saber que garante uma promessa de gozo a mais (Souza, 2003). Assim, advertindo quanto à "mutação capital" que dá "ao discurso do mestre seu estilo capitalista", Lacan (1969-1970/1992, p. 160) franqueia a inversão entre significante e sujeito, formalizando o discurso capitalista.

$\mathrm{O}$ adolescente, enodado no discurso capitalista que rege as relações na contemporaneidade, lança a si mesmo em uma aposta no gozo irrestrito, sem balizas, fora de uma lei que impõe um limite entre o possível e aquilo que não se pode ter ou fazer, pelo menos, de imediato. Um modo de resistência ao discurso capitalista seria a arte, promotora de outra relação com os objetos. Uma relação de potência graças ao poder de criar. Através da criação e não do consumo, o adolescente produz um objeto (por vezes, uma canção ou um poema), através do qual faz laço e tenta imprimir, no Outro, sua marca.

A relação com os objetos adquire novos contornos e potência na adolescência. No entanto, é preciso reconhecer, no emergente, a marca do já existente. As operações psíquicas referentes à constituição subjetiva são reativadas e vêm intensificadas por uma nova potência: o aflorar da sexualidade e a possibilidade de descarga pela maturação genital, a possiblidade de procriar (e criar) e a força física que antes não existia.

Os atos, em função dos quais os adolescentes são levados ao serviço, revelam impasses importantes em seu processo de constituição (ainda em curso) e comumente atualizam dificuldades presentes desde a infância no laço com as figuras parentais. Dificuldades que se acirraram, como afirmamos anteriormente, com a potência adquirida. Sobre os atos na adolescência, um primeiro cuidado a se tomar é que eles não podem ser naturalizados porque nessa etapa é esperada a impetuosidade ou a "tendência a agir".

A expressão "tendência a agir" teria sido forjada por André Haim em 1971 (Alberti, 2009) e nos parece importante para pensar a clínica com adolescentes. Um ponto a considerarmos é que 0 ato tem dimensões ou apresentações distintas. Na psicanálise, encontramos a distinção entre acting out e passagem ao ato. Enquanto que nessa última modalidade do ato encontramos um certo desvanecimento do sujeito na qual "ele se precipita e despenca fora de cena", o acting out "é, essencialmente, alguma coisa que se mostra na conduta do sujeito. A ênfase demonstrativa de todo acting out, sua orientação para o Outro, deve ser destacada" (Lacan, $1962-1963 / 2005$, p. 129). Concordamos com Alberti (2009) que, entre adolescentes, vemos com muita frequência actings; apelo dirigido ao Outro; no entanto, nenhuma generalização apriorística é possível fazer - a clínica continua soberana.

Em não sendo possível a generalização, é viável e pertinente, outrossim, apresentar algumas observações realizadas, a partir do projeto, entre a posição na qual os adolescentes se situam na relação com o Outro e a ocorrência de passagens ao ato e actings.
1. Relações nas quais o adolescente está posicionado como objeto de um gozo mortífero do Outro. Nessas situações, temos observado que o adolescente se manifesta em resposta a uma angústia aniquiladora através da agressividade dirigida a si mesmo ou a outro. Comumente, os atos, nesses casos, não apresentavam o estatuto de um apelo. Um caso com o qual podemos ilustrar nossa proposição é o de um adolescente levado ao serviço por apresentar isolamento extremo e alguns fenômenos alucinatórios, cujos pais são separados e que, em momentos de extrema angústia - mais particularmente quando levado à casa do pai contra sua vontade -, esfrega um pulso no outro, até que a pele se rompa. $\mathrm{O}$ ato de mutilar-se nesse caso não se traduz como apelo dirigido ao Outro; desponta como resposta a angústia que o invade e contra a qual ele não encontra outras defesas possíveis.

2. Uma relação na qual o adolescente, na infância, viveu em errância, sendo deslocado entre suas famílias e abrigos. São situações nas quais um Outro prestativo preponderantemente faltou na articulação de sua presença com sua ausência. A sistemática vivência, seja da impotência e/ou da onipotência de um Outro do qual não era possível saber o que esperar durante a infância, conduz a tentativas de fazer com que, na adolescência, o lugar que se ocupa perante o Outro seja novamente indagado através das demandas amorosas. Nos atos desses adolescentes, as fugas e outros apelos para que um Outro os tome como objeto de investimento e de cuidado são recorrentes. Com frequência, eles, por meio de seus atos, colocam-se em situações de risco, e atualizam uma questão fundamental: o valor de sua existência para o Outro.

3. Relações marcadas por um embaraço diante de duas questões: "o que sou para o Outro?" e "o que o Outro quer de mim?". Uma hipótese é que, diante desse embaraço, o adolescente responda com atos que (1) provocam a extração de um objeto de seu próprio corpo (sangue e/ou um pedaço da própria carne, ofertando esse sacrifício ao olhar do outro); (2) configuram-se como fugas que se apresentam como acting out; (3) afrontam a lei (furtos e assaltos) e (4) agridam a si mesmos (escarificações, mordidas, batem a cabeça) e/ ou a outrem (em geral mãe e irmãos) ou que destruam objetos de valor dados pelos pais com certo sacrifício (quebrar celular e laptop). Com frequência, embates com seus semelhantes ou seus pais são travados. Em particular, com os pais ou outros responsáveis, observa-se a atualização da fantasia apontada por Freud em seu texto "Bate-se numa Criança” (Freud, 1919/1987), posto que nas 
ocasiões em que o embate se dá comumente o adolescente se coloca em uma posição a partir da qual incita o Outro a machucá-lo.

Em se tratando de uma intensificação de pedidos de ajuda pela via do ato - mais actings do que passagens ao ato - a clínica com adolescentes põe em jogo questões específicas concernentes a aventura de fazer uma travessia, por vezes, em uma "canoa furada", mas também fala de uma sociedade na qual o sofrimento psíquico encontra pouco espaço para se manifestar por vias que não sejam as da medicalização.

Ao incluir o título de adolescência em atos ou adolescentes em ato, queremos chamar atenção ao enodamento entre o corte que enseja o tempo da adolescência por meio do ato. Assim o corte distingue e separa o tempo da infância do tempo do adolescer. Quais seriam as dimensões do ato capazes de demarcar um antes da adolescência e um depois da infância, dando a partida para a adolescência, quando os impasses na relação com o Outro se atualizam com a potência trazida pela puberdade? Com certeza, a expressão adolescentes em ato nos diz apenas dessa forma preponderante de ensaiar o laço social via crueza do ato, quando as palavras estão em descarrilamento e não fazem liga com o outro. Nesse caso, a série de atos dos adolescentes repetiria a tentativa de inscrição dessa diferença, tentativa esta que fracassa, tal como a repetição. Dessa forma, esses atos limitam-se a testemunhar um desenodamento dos laços anteriores, sem estarem a serviço de uma passagem rumo à assunção de uma posição subjetiva com os novos instrumentos que a adolescência traz. Não nos é possível escapar dessa dupla conotação do ato, no tempo da adolescência, e teremos que enfrentá-la, sustentando a tensão entre $\mathrm{o}$ ato enodador $\mathrm{e} o$ ato desmantelador.

\section{Adolescence and adolescents in acts in the psychoanalytic clinic}

Abstract: The paper presents a theoretical reflection on clinical experience with adolescents attended in a Psychosocial Care Center for Children and Adolescents. They came to CAPSi because of self-mutilation, suicide attempts, escapes and impulsivity expressed through aggressiveness. These events are discussed with the psychoanalytical concepts of "acting out" and "passage to the act" in psychoanalysis and Le Breton's anthropology. It was observed that the acts were presented in three situations: (1) when the young man appeared as the object of a deadly enjoyment; (2) before the fickleness of the Other; (3) when it was not possible to formulate otherwise the question of the meaning and value of self to the Other. It is argued that the acts and adolescence can be read as an appeal before the impasses experienced in finding new ways to insert in the social field.

Keywords: adolescence, psychoanalysis, passage to the act, acting out, CAPSi.

\section{L'Adolescence en actes et les actes des adolescents dans la clinique psychanalytique}

Résumé: Le document présente une réflexion théorique sur l'expérience clinique avec les adolescents ont assisté à un centre de soins psychosociaux pour les enfants et les adolescents. Les jeunes sont venus à CAPSI en fonction d'auto-mutilation, tentatives de suicide, les évasions et l'impulsivité exprimées par l'agressivité. Ces événements sont discutés à partir des concepts psychanalytiques de «acting out» et «passage à l'acte» dans la psychanalyse et l'anthropologie de Le Breton. De l'expérience, il a été observé que les actes ont été présentés dans trois situations: (1) quand le jeune homme est apparu comme l'objet d'une joie mortelle; (2) avant l'inconstance de l'Autre; (3) quand il n'a pas été possible de formuler autrement la question de la signification et de la valeur de soi même à l'autre. On soutient que les actes et l'adolescence peut être lu comme un appel devant les impasses rencontrées pour trouver de nouvelles façons d'inscrire dans le domaine social.

Mots-clés: adolescence, psychanalyse, passage à l'acte, acting out, CAPSi.

\section{Adolescencia en actos y adolescentes en acto en la clínica psicoanalítica}

Resumen: El artículo presenta una reflexión teórica sobre la experiencia clínica con adolescentes en un centro de atención psicosocial de niños y adolescentes. Los jóvenes llegaron a CAPSi en función de automutilaciones, intentos de suicidio, escapes y impulsividad expresa a través de la agresividad. Estos eventos se discuten a partir de los conceptos psicoanalíticos de "actuación" y "pasaje al acto" en el psicoanálisis y en la antropología de Le Breton. Se observó que los actos se presentan en tres situaciones: (1) cuando el joven apareció como el objeto de un goce mortal; (2) ante la inconstancia del Otro; (3) cuando no era posible formular de otra manera la cuestión del significado y del valor de sí al Otro. Se argumenta que eses actos en la adolescencia pueden leerse como un recurso ante los impasses en la búsqueda de nuevas formas de inscribirse en el social.

Palabras clave: adolescencia, psicoanálisis, pasaje al acto, acting out, CAPSi. 


\section{Referências}

Alberti, S. (2009). Esse sujeito adolescente. Rio de Janeiro, RJ: Rios Ambiciosos.

Bernardino, L. M. F. (2004). As psicoses não-decididas: um estudo psicanalítico. São Paulo, SP: Casa do Psicólogo.

Brasil, Ministério da Saúde. (2007). Saúde mental na infância e na adolescência: as politicas públicas do menor ao sujeito de direitos. Brasília, DF: Ministério da Saúde.

Freud, S. (1987). Uma criança é espancada: uma contribuição ao estudo das perversões sexuais. In Edição standard brasileira das obras psicológicas completas de Sigmund Freud (Vol. XVII, pp. 225-253). Rio de Janeiro, RJ: Imago. (Trabalho original publicado em 1919).

Lacan, J. (1972). Do discurso psicanalítico: conferência de Lacan em Milão em 12 de maio de 1972. Recuperado de https://goo.gl/acB885.

Lacan, J. (1992). O Seminário, Livro 17, o avesso da psicanálise. Rio de Janeiro, RJ: Jorge Zahar. (Trabalho original publicado em 1969-1970).

Lacan, J. (1998). O tempo lógico e a asserção de certeza antecipada. In Escritos (pp. 197-213). Rio de Janeiro, RJ: Jorge Zahar. (Trabalho original publicado em 1945).
Lacan, J. (2005). O Seminário, Livro 10, a angústia. Rio de Janeiro, RJ: Jorge Zahar. (Trabalho original publicado em 1962-1963).

Le Breton, D. (2011). Une brève histoire de l'adolescence. Paris, France: J.-C Béhar.

Lesourd, S. (2004). A construção adolescente no laço social. Petrópolis, RJ: Vozes.

Rassial, J.-J. (1999). O adolescente e o psicanalista. Rio de Janeiro, RJ: Companhia de Freud.

Rassial, J.-J. (2000). O sujeito em estado limite. Rio de Janeiro, RJ: Companhia de Freud.

Souza, A. (2003). Os discursos na psicanálise. Rio de Janeiro, RJ: Cia de Freud.

Vieira, A. A. (2014). A irrupção da puberdade e a manifestação das neuroses: um percurso na obra freudiana (Dissertação de Mestrado). Universidade Federal de Minas Gerais, Departamento de Psicologia, Belo Horizonte, MG. Recuperado de: https://bit.ly/2zhPBeb

Vorcaro, A., \& Capanema, C. (2011). Chicanas da travessia adolescente. Psicologia em Revista, 17(1), 82-99.

Recebido: $25 / 11 / 2017$

Aprovado: 15/04/2018 